\title{
Rapid Proliferation and Differentiation of a Subset of Circulating IgM Memory B Cells to a CpG/Cytokine Stimulus In Vitro
}

\author{
Camilo Vásquez, Manuel A. Franco, Juana Angel* \\ Instituto de Genética Humana, Facultad de Medicina, Pontificia Universidad Javeriana, Bogotá, Colombia \\ * jangel@javeriana.edu.co
}

\section{Abstract}

Circulating human IgM expressing memory B cells have been incompletely characterized. Here, we compared the phenotype and in vitro functional response (capacity to proliferate and differentiate to antibody secreting cells) in response to $\mathrm{CpG}$ and a cytokine cocktail (IL-2, IL-6, and IL-10) of sorted naïve B cells, IgM memory B cells and isotype-switched circulating memory B cells. Compared to naïve B cells, IgM memory B cells had lower integrated mean fluorescence intensity (iMFI) of BAFF-R, CD38, CD73, and IL-21R, but higher iMFI of CD95, CD11C, TLR9, PD-1, and CD122. Compared to switched memory $B$ cells, IgM memory B cells had higher iMFI of BAFF-R, PD-1, IL-21R, TLR9, and CD122, but lower iMFI of CD38, CD95, and CD73. Four days after receiving the $\mathrm{CpG} /$ cytokine cocktail, higher frequencies of IgM than switched memory B cells-and these in turn greater than naïve cells-proliferated and differentiated to antibody secreting cells. At this time point, a small percentage (median of $7.6 \%$ ) of stimulated IgM memory B cells changed isotype to IgG. Thus, among the heterogeneous population of human circulating $\operatorname{lgM}$ memory $B$ cells a subset is capable of a rapid functional response to a $\mathrm{CpG} /$ cytokine stimulus in vitro.

Received: April 15, 2015

Accepted: September 15, 2015

Published: October 6, 2015

Copyright: @ 2015 Vásquez et al. This is an open access article distributed under the terms of the Creative Commons Attribution License, which permits unrestricted use, distribution, and reproduction in any medium, provided the original author and source are credited.

Data Availability Statement: All relevant data are within the paper and its Supporting Information files.

Funding: This work was funded by grants 1203-52128212 from Colciencias and 5193 from Pontificia Universidad Javeriana. CV was funded by the program "Jóvenes Investigadores".

Competing Interests: The authors have declared that no competing interests exist.

\section{Introduction}

$\mathrm{B}$ cells $(\mathrm{Bc})$ and the antibodies they produce after becoming antibody secreting cells (ASC) are critical for protecting the individual from pathogens and maintaining tissue homeostasis $[1,2]$. Instrumental to the function of $\mathrm{Bc}$ is their capacity to differentiate from naïve (nonantigen experienced) to antigen experienced memory $\mathrm{Bc}(\mathrm{mBc})$ [1]. This process renders $\mathrm{mBc}$ capable of promptly responding to a second encounter with a pathogen and is reflected by their propensity to rapidly proliferate and differentiate in vitro, in an antigen independent fashion, to T cell dependent (CD40L) and independent stimuli $[3,4]$. As an example of the latter, it has been shown that naïve cells depend on $\mathrm{Bc}$ receptor signaling, while $\mathrm{mBc}$ are activated by $\mathrm{CpG}$ and cytokines, without need for $\mathrm{Bc}$ receptor stimulation [5]. In mice, $\mathrm{mBc}$ can be derived independently of a germinal center $\left(\mathrm{GC}^{-}\right.$, mostly IgM with low frequency of 
mutations) or dependently on the germinal center $\left(\mathrm{GC}^{+}\right.$, mostly isotype-switched with high frequency of mutations) [6-9]. It is unclear if an equivalent population of $\mathrm{GC}^{-}$exists among human $\mathrm{mBc}$ [1]. In addition to naïve $\mathrm{Bc}$ and different subsets of $\mathrm{mBc}, \mathrm{Bc}$ with innate function (non-antigen experienced) has been described in the blood and spleen of mice and humans $[2,10-12]$. In the murine spleen marginal zone Bc have unmutated BCR and are capable of rapidly responding to bloodborne $\mathrm{T}$ cell-independent antigens [12]. Recently, in humans, it has been shown that both spleen and circulating IgM mBc contain a populations of cells that differentiates to marginal zone-like $\mathrm{Bc}$, as its mouse counterpart, through a NOTCH2 signaling pathway [10].

Being able to discriminate all subsets of human Bc by their phenotype has been a challenging enterprise since the discovery of $\mathrm{CD} 27$ as a marker of $\mathrm{mBc}$ [13]. This marker is not an absolute marker of $\mathrm{mBc}$ [14] and, to date, at least six $\mathrm{mBc}$ subsets have been defined, based on their differential expression of $\mathrm{CD} 27$ and IgH isotypes [15]. These diverse subtypes of $\mathrm{mBc}$ were characterized for their differential replication history and Ig gene repertoire and somatic mutations in the Ig genes [15]. However, at present, it is uncertain how to phenotypically discriminate human innate $\mathrm{Bc}[10,16]$ from "true" antigen experienced IgM mBc that may share key features (expression of both IgM and IgD and low number of mutations in their Ig genes) [1, 11].

We and others have previously shown that rotavirus specific $\mathrm{mBc}$ (detected by flow cytometry with a labeled rotavirus antigen) are enriched in the $\mathrm{CD} 27^{+} \mathrm{IgM}^{+} \mathrm{mBc}$ and $\mathrm{CD} 27^{-} \mathrm{mBc}$ [17-20]. Moreover, we have shown that Total (non-antigen specific) and rotavirus -IgM mBc detected with a seven day limiting dilution assay - in which $\mathrm{Bc}$ are stimulated to produce antibodies with CpG, a cocktail of cytokines (IL-2, IL-6, and IL-10) and murine fibroblasts (as feeder cells) - are differentially capable of switching in vitro to secrete IgG [18]. Notably, this stimulus was optimized to preferentially activate $\mathrm{mBc}$ over naïve $\mathrm{Bc}$ and to induce the former to differentiate to ASC $[17,18,21]$. In these assays, the median cloning efficiencies of Total $\mathrm{IgM}^{+}$and rotavirus $-\mathrm{IgM}^{+} \mathrm{mBc}$ were lower than those of the corresponding switched $\mathrm{mBc}$. The functional importance of $\operatorname{IgM~} \mathrm{mBc}$ was evidenced by experiments in which purified IgM $\mathrm{mBC}$ transferred to immunodeficient mice infected with rotavirus were capable of switching isotype and of controlling antigenemia and viremia [18].

A comprehensive functional study of $\mathrm{mBc}$ subsets must include $\mathrm{Bc}$ from different tissues, as exemplified by experiments in which $\mathrm{mBc}$ with the same phenotype, but originating from blood or tonsils, respond differently in vitro to T cell independent (CpG) and T cell dependent (CD40L) based stimuli [22]. However, a functional comparison of blood $\mathrm{mBc}$ subsets to $\mathrm{mBc}$ from other organs is hampered by their low numbers in blood. To date, few studies have contrasted the function of IgM and switched circulating $\mathrm{mBc}$ [5, 23-25].

Here, we compared the phenotype and in vitro functional response of sort purified circulating naïve $\mathrm{Bc}$ and IgM and switched $\mathrm{mBc}$ in response to $\mathrm{CpG}$ and a cocktail of cytokines (IL-2, IL-6, and IL-10) previously described [18]. Compared to naïve B cells, IgM mBc had lower iMIF of BAFF-R, CD38, CD73, and IL-21R, but higher iMIF of CD95, CD11c, TLR9, PD-1, $\mathrm{CD122}$, and CD45RO. Compared to switched $\mathrm{mBc}$, IgM mBc had higher iMFI of BAFF-R, PD-1, IL-21R, TLR9, and CD122, but lower iMFI of CD38, CD95, and CD73. Higher frequencies of IgM $\mathrm{mBc}$ than switched $\mathrm{mBc}$-and these in turn greater than naïve cells-proliferated and differentiated to ASC four days after receiving the $\mathrm{CpG} /$ cytokine cocktail. At this time point after the stimulus a small percentage (7.6\%) of IgM mBc changed isotype to IgG. We conclude that among the heterogeneous population of circulating IgM memory $\mathrm{Bc}$, a subset is capable of a rapid functional response in vitro to a $\mathrm{CpG}$ based polyclonal stimulus. These functional studies may aid in discriminating IgM Bc subpopulations. 


\section{Materials and Methods}

\section{Flow cytometry analyses}

This project was approved by the ethics committee of the School of Medicine of Pontificia Universidad Javeriana FM-CIE-5166-10. Healthy adult volunteers signed informed consent forms approved by the ethics committee of the School of Medicine of Pontificia Universidad Javeriana. Ficoll gradient purified PBMCs, were suspended in $1 \mathrm{X}$ PBS with $0.5 \%$ bovine serum albumin (BSA, Sigma-Aldrich, St. Louis) and $0.02 \%$ sodium azide (Mallinckrodt Chemicals, Paris, $\mathrm{Ky}$ ) and stained with monoclonal antibodies (all from BD Bioscience U.S. unless otherwise stated) against (labeled, clone): CD3 (V500, UCHT1), CD14 (V500, M5E2), CD19 (APC-H7, SJ25C1), CD38 (PerCp-Cy5.5 or AF 700, hit2), CD27 (PE-CF594, M-T271), IgD (VB421, IA62), IgM (PerCp-Cy5.5 or AF700, G20-127 and 145-8, respectively), CD40 (PeCy7, 5C3), IL2R $\beta$ /CD122 (PE, Mik- $\beta 3$ ), TLR9 (PE, eB72-1665), CD95 (PE, DX2), CD73 (PE, AD2), CD21 (PE, Bly-4), IL-21R (PE, 17A12), CD45RO (APC, uch1), CD11c (APC, S-HCL-3), BAFF-R (APC, 11C1), CD43 (APC, eBio84-3C1) (eBioscience U.S. San Diego, CA), PD-1 (PE, J105) (eBioscience U.S. San Diego, CA), and CX3CR1 (APC, 2A9-1) (Biolegend, U.S, San Diego, $\mathrm{CA}$ ), on ice for $30 \mathrm{~min}$ [for all the markers analyzed a FMO was include as a negative control (S2 Fig)]. Samples were acquired on a LSR Fortessa (BD Biosciense) and analyzed using FlowJo v.9.3.2. The data are represented as an integrated mean fluorescent intensity (iMFI = percentage of positive cells $\times \mathrm{MFI}$ ), a metric measure that combines magnitude (percentage of cells expressing a marker) and quality (MFI of this same marker) and reflects the total potential functional response of each cell subset [26,27].

\section{Sorting of Bc subpopulations}

The Hemocentro Distrital, Bogotá, Colombia, provided buffy coats from de-identified healthy donors that signed informed consent forms. From these buffy coats, an enriched suspension of circulating B cells was obtained by negative selection by rosette formation (StemCell Biotech, Vancouver, Canada), as previously described [18]. The enriched B cells were suspended in sterile PBS and stained on ice with AQUA (Invitrogen Molecular Probes U.S. MA, Waltham) and subsequently with antibodies (all from BD Bioscience) against (labeled): CD3/CD14 (V500), CD19 (APC-H7), CD38 (PerCp-Cy5.5), CD27 (PE-CF594), IgD (VB421), IgG (APC G18145), and IgM (APC polyclonal) (Jackson Immunoresearch U.S. PA, West Grove) for 30 minutes on ice. Samples were sorted using a FACSAria IIu (BD Bioscience) and cell purities were above 95\%. Cells were recovered in RPMI supplemented with $2 \mathrm{mM} \mathrm{L}$-glutamine, $100 \mathrm{U} / \mathrm{ml}$ penicillin, $100 \mu \mathrm{g} / \mathrm{ml}$ streptomycin, $0.1 \mathrm{mM}$ non essential amino acids, $1 \mathrm{mM}$ sodium pyruvate, $0.05 \mathrm{mM} \beta$-mercaptoethanol and 20\% Fetal bovine serum (FBS), from now on referred to as complete medium.

\section{Stimulation and analyses of sort purified Bc}

B cells subpopulations were labeled with carboxyfluorescein succinimidyl ester (CFSE), as previously described [28], with minor modifications. Bc were washed twice with sterile PBS and stained (0.4-1 x $10^{6}$ cells/ml) with CFDA-SE (Cell-TraceTM CFSE Cell Proliferation Kit, Invitrogen Molecular Probes) for $5 \mathrm{~min}$ at room temp protected from light. After being washed three times with $10 \mathrm{ml}$ of PBS $5 \%$, FBS $5 \%$, naïve $\mathrm{Bc}$ and $\mathrm{IgM} \mathrm{mBc}$ and switched $\mathrm{mBc}$ were stimulated, as previously described [18], adapting the limiting dilution assays conditions to stimulation in a 48 well format: Bc were stimulated with $2.5 \mu \mathrm{g} / \mathrm{ml}$ of CpG (ODN 2006; InvivoGen, San Diego, CA), $10 \mathrm{ng} / \mathrm{ml}$ human recombinant IL-2, $10 \mathrm{ng} / \mathrm{ml}$ human recombinant IL-6, 15 ng/ml IL-10 (all cytokines from PreproTech, Rocky Hill, New Jersey), and NIH 3T3 murine 
fibroblasts (ATCC Manassas, VA, USA). The NIH 3T3 feeder cells were irradiated with 3,000 rads (Radiotherapy unit, Centro Javeriano de Oncología, Bogotá) and then used at a concentration of 5,000 cells/well. B cells (20,000 in $200 \mu \mathrm{l}$ of complete medium with $10 \%$ FBS) were cultured at $37^{\circ} \mathrm{C}$ with $5 \% \mathrm{CO}_{2}$ in flat bottom 48 well plates for different periods of time. At the end of the cultures, cells were washed twice with sterile PBS and stained on ice with AQUA (Invitrogen Molecular probes) and subsequently with antibodies (all from BD Bioscience) against (labeled): CD19 (APC-H7), CD38 (PerCp-Cy5.5), CD27 (PE-CF594). After washing, cells were resuspended in $100 \mu \mathrm{lBS}, 0.5 \% \mathrm{BSA}$ (Sigma-Aldrich) plus $250 \mu \mathrm{l}$ of cytofix/cytoperm (BD Pharmingen) and incubated for $20 \mathrm{~min}$ at $4^{\circ} \mathrm{C}$. After washing twice with perm/wash (BD Pharmingen) cells were stained with antibodies against IgM APC (Jackson ImmunoResearch) or IgG APC (BD Bioscience) for $30 \mathrm{~min}$ on ice. Samples were acquired on a LSR Fortessa (BD Bioscience) and analyzed using FlowJo v.9.3.2 (FlowJo, LLC, U.S. OR).

\section{Statistical analyses}

Since data was not normally distributed, non parametric tests were used for comparisons. Differences among groups were determined using Kruskal-Wallis tests followed by a Wilcoxon signed-rank test using GraphPad Prism software v.5.0a for Mac OS X, GraphPad Software (La Jolla, CA). Significance was established if $\mathrm{p}<0.05$. Data are shown as median and interquartile range.

\section{Results}

\section{Phenotypic differences of naïve $\mathrm{Bc}, \operatorname{IgM~mBc}$, and switched $\mathrm{mBc}$}

$\mathrm{Bc}(\mathrm{CD} 19+)$ were separated into naïve $\left(\mathrm{CD}^{-} 7^{-} \mathrm{IgD}^{+}\right.$: the transitional $\mathrm{Bc}$ subset was not excluded from the analysis), $\operatorname{IgM~} \mathrm{mBc}\left(\mathrm{CD} 27^{+} \operatorname{IgD}^{+} \operatorname{IgM}^{+}\right.$: which included the IgM only but not the IgD only subpopulations) and switched $\mathrm{mBc}\left(\mathrm{CD} 27^{+} \operatorname{IgD}^{-} \operatorname{IgM}^{-}\right)$, as described in Fig $1 \mathrm{~A}$ and $1 \mathrm{~B}$ and S1 Fig. For each of the three Bc subpopulations, we evaluated the expression of 12 markers and histograms for one of these (CD95) is shown in Fig $1 \mathrm{C}$, as an example. The selected markers evaluated were: CD40, BAFF-R, CD95, PD-1, IL-21R, CD73, CD43, CD11c, CD21, CD38, TLR9, and CD122. A summary of the experiments is shown in Fig 2 were data is represented as iMFI, a metric measure that combines magnitude and quality. Histograms for each individual marker are shown in $\mathrm{S} 2$ Fig.

The iMFI of CD40 and CD21, a part of the Bc co-receptor [29] and considered a molecule highly expressed on marginal zone $\mathrm{Bc}$ [30], were comparable among $\mathrm{Bc}$ subsets (Fig 2, first row). BAFF-R iMFI was high among $\mathrm{Bc}$ and significantly higher in naïve $\mathrm{Bc}$ (Fig 2, first row).

The iMFI of CD38, CD73, and CD95 were intermediate to low in the three $\mathrm{Bc}$ subsets (Fig 2, second row). $\mathrm{CD} 38$ is an ADP-ribosyl cyclase and its iMFI was higher in naïve $\mathrm{Bc}$ than both switched $\mathrm{mBc}$ and IgM $\mathrm{mBc}$. In agreement with previous results, the iMFI of CD73 (an ectoenzyme that degrades extracellular nucleoside monophosphates to adenosine) of naïve $\mathrm{Bc}$ was comparable to that of switched $\mathrm{mBc}$, but higher than that of IgM $\mathrm{mBc}$ [31]. The expression of CD95 is associated with caspase dependent apoptosis [32] and, as previously reported, CD95 iMFI of naïve Bc was comparatively very low [4, 32]. Also, CD95 iMFI of IgM mBc was significantly lower than that of switched $\mathrm{mBc}$.

The iMFI of CD11c a marker shown to be expressed by IgM $\mathrm{mBc}$ specific for bacteria in mice [33], was intermediate and similar for IgM and switched $\mathrm{mBc}$, but lower for naïve Bc (Fig 2, third row).

Similar low iMFI of CD43, a marker that has been proposed to identify B1 Bc in humans [16] were identified in the three Bc subset studied (Fig 2, third row). 

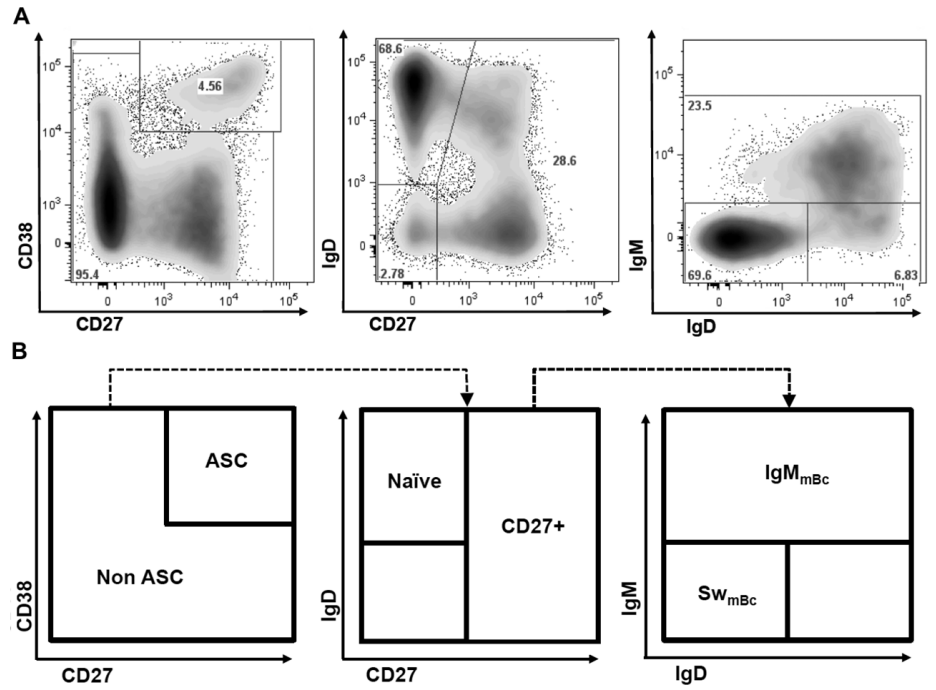

C Naïve
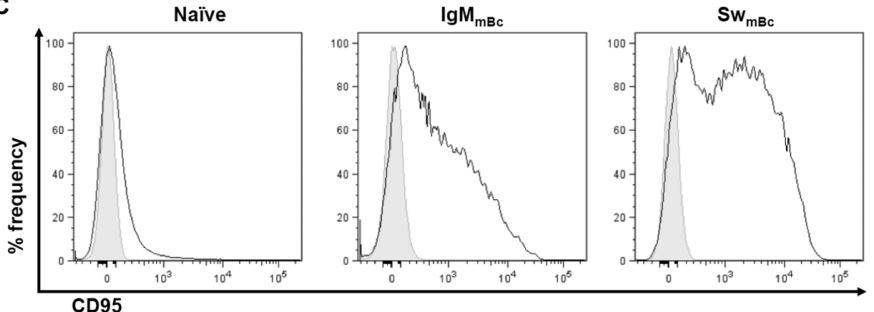

Fig 1. Flow cytometry analysis strategy. Representative dot plots $(\mathbf{A})$ and the corresponding strategy (B) to identify on a gate of circulating Bc (CD19+ $\left.\mathrm{CD}^{-} / \mathrm{CD} 14^{-}\right)$that excludes CD38 ${ }^{\mathrm{hi}}, \mathrm{CD} 27^{\mathrm{hi}}$ ASC the Bc populations of interest: naïve $\left(\mathrm{CD}^{-} 7^{-} \mathrm{IgD}^{+}\right)$, $\operatorname{lgM~mBc}\left(\mathrm{CD} 27^{+} \operatorname{IgD}^{+} \operatorname{IgM}^{+}\right)$and switched $(\mathrm{Sw}) \mathrm{mBc}\left(\mathrm{CD} 27^{+} \operatorname{lgD}\right.$ $\left.\operatorname{lgM}^{-}\right)$. Different markers were studied for each Bc subset; shown are representative histograms for CD95. Solid gray histogram represents fluorescence minus one (FMO) and the continuous solid line shows staining with anti-CD95 (C).

doi:10.1371/journal.pone.0139718.g001

The iMFI of CD122, the beta chain of the IL-2 and IL-15 receptors, TLR9, the receptor for $\mathrm{CpG}$, and $\mathrm{PD}-1$, which regulates activation and survival of $\mathrm{Bc}$ [34], were low for the three $\mathrm{Bc}$ subsets, but significantly higher in IgM $\mathrm{mBc}$ than naïve $\mathrm{Bc}$ or switched $\mathrm{mBc}$ (Fig 2, third row and fourth row, respectively). However, both IgM and switched $\mathrm{mBc}$ express more intracellular TLR9 than naïve cells, but no differences were seen between IgM and switched $\mathrm{mBc}$ (S3 Fig).

Finally, in agreement with previous reports [35], higher iMFI of IL-21R, a key molecule critically implicated in $\mathrm{Bc}$ activation [36], was detected for naïve cells than switched $\mathrm{mBc}$ (Fig 2, fourth row). We also compared the expression of $\mathrm{CD} 45 \mathrm{RO}$ (data not shown), which resembled the expression of CD43 (Fig 2).

\section{A subset of IgM mBc rapidly proliferate and differentiate to ASCs in vitro in response to $\mathrm{CpG}$ and cytokines}

To compare the capacity to proliferate and differentiate to ASC $\left(\mathrm{CD} 27^{\text {hi }} \mathrm{CD} 38^{\text {hi }}\right)$ of naïve $\mathrm{Bc}$ and IgM and switched $\mathrm{mBc}, \mathrm{Bc}$ were enriched from buffy coats of blood bank volunteers by rosette formation and subsequently each subset was purified by the sorting strategy described in Fig 3. Bc were then labeled with CFSE and stimulated with CpG, a cocktail of cytokines (IL2, IL-6, and IL-10) and murine fibroblasts (as feeder cells) for two, three, four, and five days. The peak response for proliferation and differentiation to ASC $\left(\mathrm{CD} 27^{\text {hi }} \mathrm{CD} 38^{\text {hi }}\right)$ was between days three and four, for both types of $\mathrm{mBc}$ (S4 Fig). Four days after stimulation a higher 

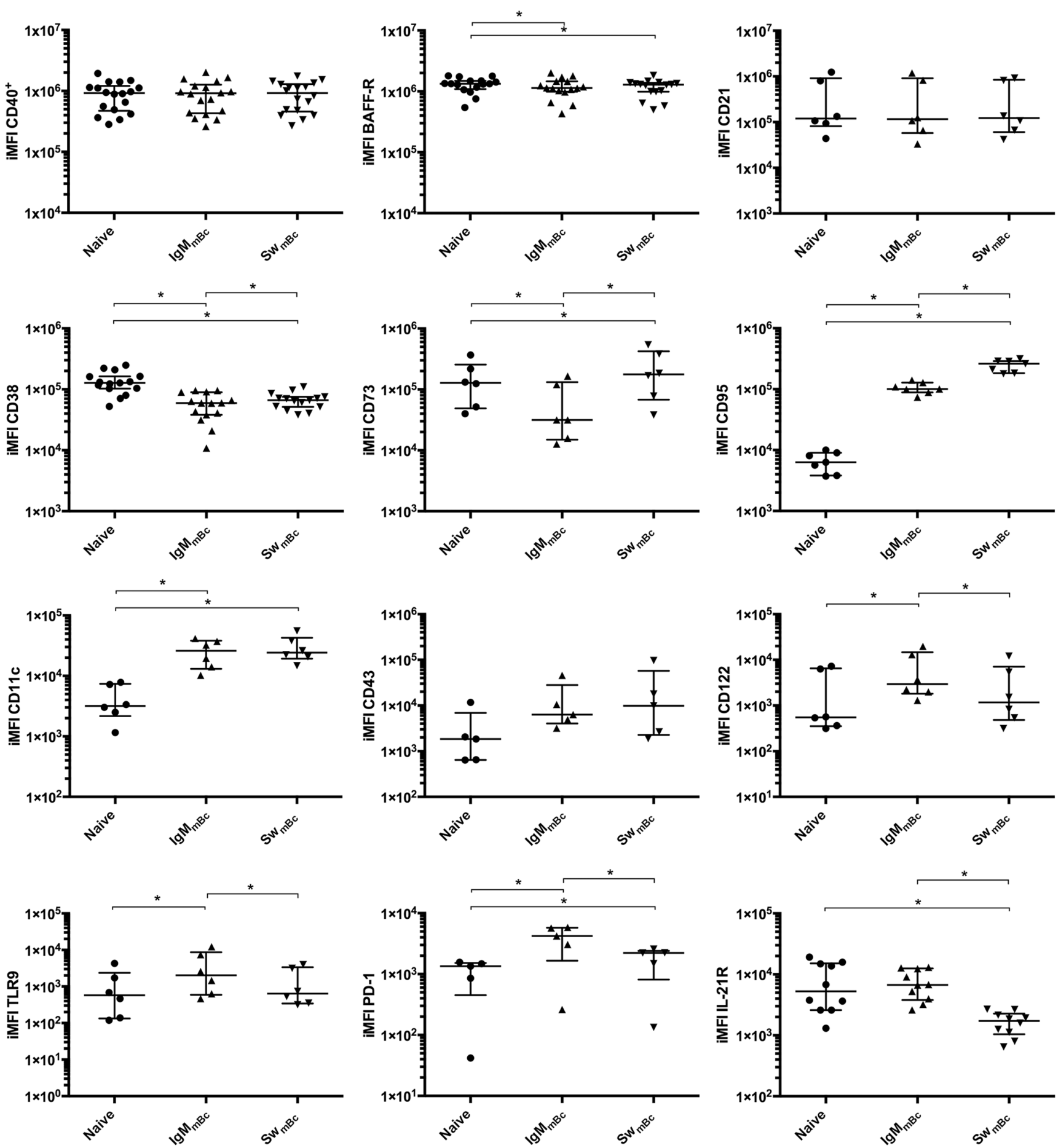

Fig 2. Phenotypic profile of the three Bc subsets. A summary of the experiments to characterize the phenotype of circulating naïve $B c$ and lgM and switched (Sw) mBc in PBMC from healthy adult volunteers is presented: CD40 ( $n=18)$, BAFF-R $(n=16), \operatorname{CD} 21(n=6)$, CD38 $(n=15)$, CD73 $(n=6)$, CD95 $(n=7), \operatorname{CD11C}(n=6), \operatorname{CD} 43(n=5)$, CD122 $(n=6)$, TLR9 $(n=5)$, PD-1 $(n=5)$, and IL-21R $(n=10)$. Wilcoxon tests were used for evaluating differences among groups and * denotes $p<0.05$. Individual results are shown (as iMFI) and lines and error bars denote the median and interquartile range, respectively.

doi:10.1371/journal.pone.0139718.g002 

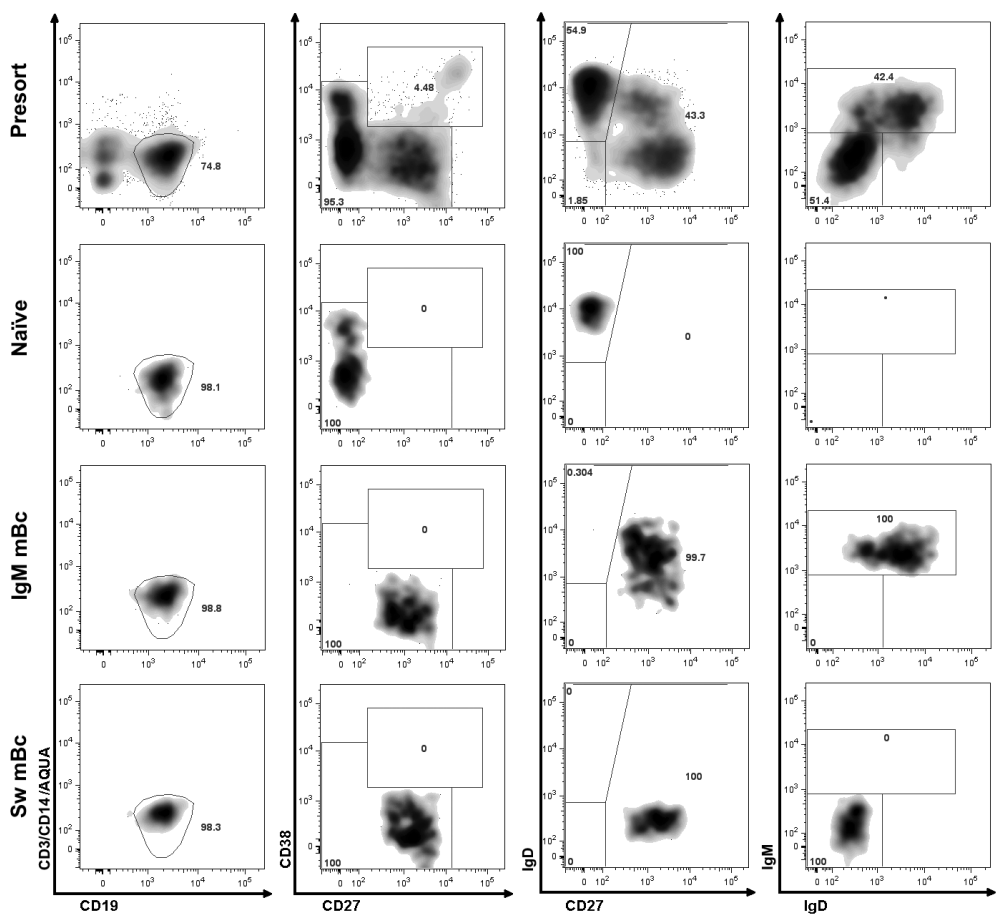

Fig 3. Sorting strategy for purification of the three Bc subsets. Representative dot plots of a sorting experiment to purify naïve $\mathrm{Bc}$ and $\mathrm{IgM}$ and switched $(\mathrm{Sw}) \mathrm{mBc}$. Dot plots of presort samples are shown in top rows. Dot plots of naïve $\mathrm{Bc}$ and $\operatorname{lgM}$ and $\mathrm{Sw} \mathrm{mBc}$ are shown in the second, third, and fourth rows, respectively. Cells were initially gated on $\mathrm{CD} 19^{+}$dump channel (Aqua, CD3, CD14), first column. After excluding CD38 ${ }^{\text {hi }}, C D 27^{\text {hi }}$ ASC (second column), naïve cells were gated as CD27 IgD (third column) and the $\mathrm{CD} 27^{+}$subset was sorted as $\operatorname{lgM}^{+}$or switched ( $\left.\operatorname{lgM}^{-}\right) \mathrm{mBc}$ (fourth column).

doi:10.1371/journal.pone.0139718.g003

frequency of IgM $\mathrm{mBc}$ proliferated (Fig $4 \mathrm{~A}$ and $4 \mathrm{~B}$ ) and acquired the phenotype of ASC, compared to switched $\mathrm{mBc}$ and naïve $\mathrm{Bc}$ (Fig $4 \mathrm{D}$ ). It has been previously shown that, in general, naïve $\mathrm{Bc}$ have undergone a lower number of divisions (two divisions) than IgM $\mathrm{mBc}$ (seven divisions) and switched $\mathrm{mBc}$ (10 divisions) [15], and that the number of divisions a $\mathrm{Bc}$ has performed limits the maximum additional divisions it can undertake [37]. In agreement with this, we found that the MFI CFSE-which is inversely proportional to the number of divisions a $\mathrm{BC}$ has performed in vitro after stimulation-was lower in the IgM $\mathrm{mBc} v s$. switched $\mathrm{mBc}$ (Fig $4 \mathrm{C})$.

\section{A subset of stimulated IgM mBc rapidly change isotype in vitro after stimulation}

Our group has previously shown that a median of $62 \%$ IgM mBc stimulated for seven days in a limiting dilution assay, with the same stimulus as we have used here, switch to IgG [18]. To determine if isotype switch occurred in $\operatorname{IgM~} \mathrm{mBc}$ under the present stimulation conditions (four days), we stained $\mathrm{Bc}$ for intracellular IgM and IgG (Fig 5A). Coherent with our initial results, we observed an isotype switch to IgG in a median of 7.6\% (range 2-20\%) of IgM mBc four days after stimulation (Fig $5 \mathrm{~A}$ and $5 \mathrm{C}$ ). As expected, very low or no naïve $\mathrm{Bc}$ expressed IgG and no, or very low, numbers of switched $\mathrm{mBc}$ expressed IgM. Of note the median IgG expression on switched $\mathrm{mBc}$ was $34.4 \%$ because the subset was sorted as IgD-, IgM-cells that include IgA an IgE cells. Intracellular IgG expression was not found on purified naïve Bc and $\mathrm{IgM} \mathrm{mBc}$ prior in vitro stimulation (S5 Fig). 
A

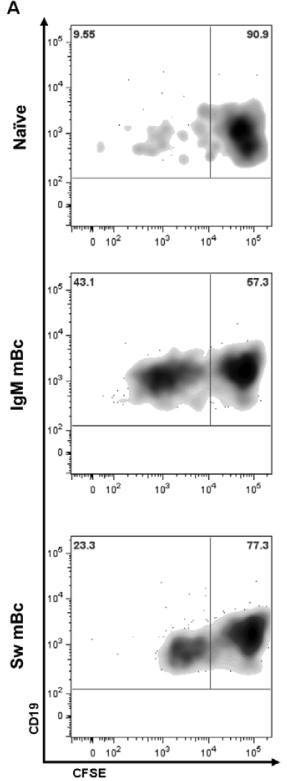

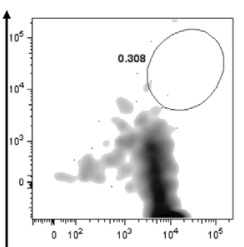

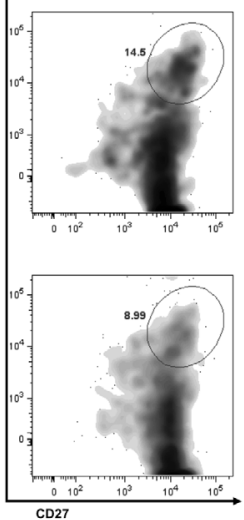

B
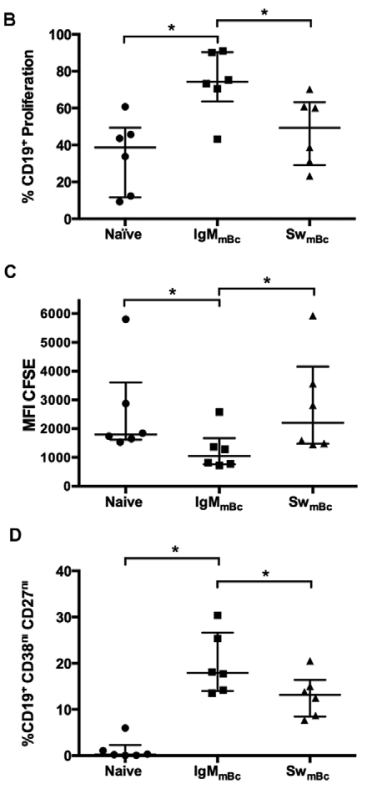

Fig 4. Proliferation and differentiation to $A S C$ of the three $B c$ four days after in vitro stimulation. Representative dot plots of proliferation (first column) and differentiation to ASC (CD38 ${ }^{\text {hi }}$ CD2 $7^{\text {hi }}$ ) (second column) of naïve $\mathrm{Bc}$ and $\mathrm{IgM}$ and switched $\mathrm{mBc}$ four days after stimulation with $\mathrm{CpG}$, a cocktail of cytokines (IL-2, IL-6, and IL-10), and murine fibroblasts (as feeder cells) (A). Summary of experiments for percentages of CFSE ${ }^{\text {low }}$ proliferating Bc (B), MFI of CFSE ${ }^{\text {low }}$ cells (C), and frequencies of CD38 ${ }^{\text {hi }}$ CD27 $7^{\text {hi }}$ ASC (D) of each of the Bc studied. Wilcoxon tests were used for evaluating differences among groups and * denotes $p<0.05$. Individual results are shown and lines and error bars denote the median and interquartile range, respectively.

doi:10.1371/journal.pone.0139718.g004
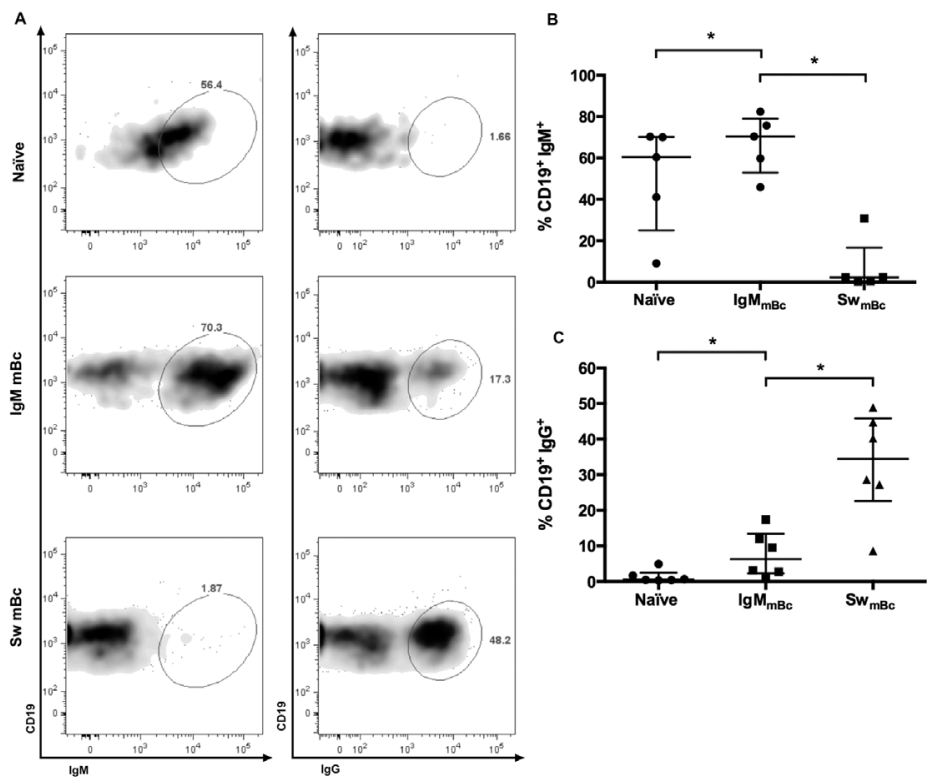

Fig 5. Intracellular expression of IgM and IgG of the three Bc subsets four days after in vitro stimulation. Representative dot plots of an experiment to evaluate intracellular IgM and IgG after stimulation of naïve $\mathrm{Bc}$ and $\mathrm{IgM}$ and switched $\mathrm{mBc}(\mathbf{A})$. Summary of experiments for the percentages of cells expressing $\lg M(B)$ and $\lg G(C)$ are shown. Wilcoxon tests were used for evaluating differences among groups and * denotes $p<0.05$. Individual results are shown and lines and error bars denote the median and interquartile range, respectively.

doi:10.1371/journal.pone.0139718.g005 


\section{Discussion}

Comparison of the functional capabilities of switched and IgM mBc may help in better discriminating human $\mathrm{Bc}$ subsets. Here, we have shown that four days after stimulation with a CpG/cytokine cocktail (IL-2, IL-6, and IL-10) (Fig 4), a higher frequency of circulating IgM $\mathrm{mBc}$ proliferate and differentiate in vitro to ASC $\left(\mathrm{CD} 38^{\text {hi }} \mathrm{CD} 27^{\text {hi }}\right)$ compared to switched $\mathrm{mBc}$ and naïve $B c$, and a subset of IgM mBc are already capable of switching to IgG (Fig 5). We have also identified/corroborated phenotypic differences between the three Bc subpopulations, which may help explain this functional behavior (Fig 2).

Antigen independent functional response to $\mathrm{T}$ cell dependent (CD40L) or independent ( $\mathrm{CpG}$ ) stimuli (in the absence or presence of multiple cytokines) of human spleen naïve $\mathrm{Bc}$ and IgM and switched $\mathrm{mBc}$ have been extensively compared [3, 4, 38, 39]. In general, these studies have reported important differences between the naïve and $\mathrm{mBc}$, but only minor or no dissimilarities between the two $\mathrm{mBc}$ subsets: higher frequencies of $\operatorname{IgM}$ and switched spleen $\mathrm{mBc}$ differentiate to ASC in response to CD40L, compared to naïve Bc [40]. A greater proportion of human spleen switched $\mathrm{mBc}$ than IgM $\mathrm{mBc}$ was induced to proliferate after stimulation with CD40L, IL-2, IL-10, and IL-21 [3, 4, 38]. In contrast, and in agreement with our results with blood Bc (Fig 4), when spleen IgM and switched $\mathrm{mBc}$ were stimulated with $\mathrm{CpG}$ a higher percentage of IgM mBc than switched $\mathrm{mBc}$ proliferated [4]. Also, the differentiation rates to ASC of the two spleen $\mathrm{mBc}$ have been comparable or slightly different, depending on the cytokine used for co-stimulation [40]. Extrapolation of these results to $\mathrm{Bc}$ from other organs has been put in doubt by experiments showing that $\mathrm{Bc}$ from human tonsils differ functionally from $\mathrm{Bc}$ subsets with the same phenotype isolated from blood [22]. Thus, a comprehensive analysis of B cell subsets must include functional studies of B cells from different organs including blood, like in the present study.

Studies that have compared blood naïve $\mathrm{Bc}$ and $\operatorname{IgM}$ and switched $\mathrm{mBc}$ are scarce: while (in agreement with our results, Fig 4) higher frequencies of blood $\operatorname{IgM~mBc}$ seem to proliferate in response to $\mathrm{CpG}$, switched $\mathrm{mBc}$ appear to better respond to an alloreactive $\mathrm{T}$ cell clone [5]. After stimulation with Staphylococcus aureus Cowan, IL-2, IL-10, and anti-CD40 for eight days, a similar differentiation of $\mathrm{CD}_{2} 7^{+} \mathrm{IgD}^{+} \mathrm{mBc}$ (most probably IgM $\mathrm{mBc}$ ), and $\mathrm{CD}_{2} 7^{+} \mathrm{IgD}^{-}$ $\mathrm{mBc}$ (most probably switched $\mathrm{mBc}$ ) to $\mathrm{CD}^{+} 8^{+} \mathrm{ASC}$ was observed [23]. More recently, it has been shown that blood IgM $\mathrm{mBc}$ (excluding IgM only $\mathrm{mBc}$ ) share a similar gene expression pattern with switched $\mathrm{mBc}$ [25]. Notwithstanding, in response to a BCR stimulus, in the presence or absence of $\mathrm{CD} 40 \mathrm{~L}, \mathrm{IgM} \mathrm{mBc}$ up regulate markers that permit them to migrate to B-cell follicles, whereas activated IgG $+\mathrm{mBc}$ preferentially showed a plasma cell differentiation. In this study it was also shown that T-independent stimulus, like terbutaline and CEACAM8, preferentially stimulated IgM $\mathrm{mBc}$, while $\mathrm{CD} 40 \mathrm{~L}$ (a T-dependent stimulus) preferentially stimulates switched $\mathrm{mBc}$ [25]. This last study highlights the plasticity of $\operatorname{IgM~} \mathrm{mBc}$ that respond differently depending on the stimulation protocol. For this reason it is important to note that our results maybe be restricted to our stimulation procedure (based on $\mathrm{CpG}$ and cytokines), which was previously standardized for the study of antigen specific $\mathrm{mBc}[17,18,21]$. In our previous experiments stimulating purified IgM and switched $\mathrm{mBc}$, but in a limiting dilution assay for seven days, we found a higher cloning efficiency in the latter, which was accompanied, at this time point, by induction of higher frequencies of ASC identified by flow cytometry and ELISPOT [18]. Altogether, these results and our new findings (Fig 4) suggest that IgM $\mathrm{mBc}$ proliferate and differentiate more rapidly than switched $\mathrm{mBc}$ in response to $\mathrm{CpG} /$ cytokines, but that with time a greater proportion of switched $\mathrm{mBc}$ can become functional [18]. Finally, in support for a selective effect of $\mathrm{CpG}$ on IgM mBc, it has been shown that in blood $\mathrm{CD} 27^{+} \mathrm{mBc} \mathrm{CpG}$ induced increased IgM secretion, compared to CD40L [41]. 
Our results showing that IgM $\mathrm{mBc}$, but not naïve $\mathrm{Bc}$, can change isotype to IgG by day four (Fig $5 \mathrm{~A}$ and $5 \mathrm{~B}$ ) are coherent with previous studies in which cells were stimulated with CD40L, IL-2, and IL-10 for 10 days [24]. However, in the study that compared CD27 ${ }^{+} \mathrm{IgD}^{+}$and $\mathrm{CD}_{2} 7^{+} \mathrm{IgD}^{-} \mathrm{mBc}$ stimulated with CD40L and IL-2 or SAC plus IL-2 for eight days no isotype switch was seen in the $\mathrm{IgD}^{+} \mathrm{CD} 27^{+}$(mainly IgM mBc) [23]. Nonetheless, when IL-10 was added to the $\mathrm{Bc}$ cultures, IgM $\mathrm{mBc}$ were shown to secrete IgG two to three days after stimulation [23]. Altogether, these reports are in agreement with our findings (Fig 5), indicating that $\mathrm{IgM} \mathrm{mBc}$ can rapidly change isotype to a non $\mathrm{BCR}$ stimulus, but that this is dependent on the presence of cytokines like IL-10, similar to what has been reported for spleen IgM mBc [40].

Naïve $B c$ and IgM and switched $\mathrm{mBc}$ were shown to have several phenotypic differences (Fig 2). Compared to switched $\mathrm{mBc}$, IgM mBc had higher iMFI of molecules involved in the activation of Bc, such as TLR9 [5, 41, 42], IL-21-R [43], and CD122 [44] (Fig 2). Of these markers the expression of TLR9 and CD122 may partially explain the higher proliferative and capacity to differentiate to ASC of IgM mBc compared to switch $\mathrm{mBc}$ in our assay (Fig 4). Activation through TLR9 has been shown to selectively provoke proliferation of $\mathrm{mBc}$ and in particular of $\operatorname{IgM~mBc}[5,41,42]$. In agreement with our results for surface protein (Fig 2), a tendency to higher expression of TLR9 mRNA has been shown in IgM mBc than in naïve $\mathrm{Bc}$ and switch $\mathrm{mBc}$ [45]. Although this difference may explain in part the functional differences of IgM and switched $\mathrm{mBc}$ (Figs 3, 4 and 5), this interpretation must be taken with precaution because most of this receptor is expressed intracellularly [4] and when we measured intracellular TLR9 no differences were observed between IgM and switched $\mathrm{mBc}$ (S3 Fig). Since we included IL-2 in the $\mathrm{Bc}$ cultures, higher expression of CD122 (the IL-2 receptor) on IgM mBc could also partially explain the increased proliferation of these cells (Figs 3, 4 and 5). Because we also included IL-10 and IL-6 in our cultures, higher expression of IL-10R but lower expression of IL-6R mRNA by IgM mBc than in switched $\mathrm{mBc}$ [25] may also modulate the increased proliferation/differentiation of the former. Compared to switched $\mathrm{mBc}$ lower frequencies of IgM $\mathrm{mBc}$ express CD95 (Fig 2), which regulates Bc survival [32]. The expression of this marker on $\mathrm{mBc}$ may also give them an in vitro survival advantage that could be reflected on their increased proliferation frequencies (Fig 4).

The capacity of a cell to switch has been related to the presence of CD40 [46], BAFF-R [47], CD73 [31], IL21R [43] and TLR9 [48]. Of these markers, CD73 seems like a good marker to identify the subset of $\operatorname{IgM~} \mathrm{mBc}$ that switch in vitro in response to our stimulus (Fig 5). In favor of this hypothesis, it was recently reported that the presence of CD73 correlated with the capacity to switch isotype of $\operatorname{IgM~mBc}$ [31]. Moreover, in mice, $\mathrm{CD}^{+} 3^{+} \mathrm{mBc}$ are enriched in those with somatic mutations [9] and $\mathrm{GC}^{-} \mathrm{IgM} \mathrm{mBc}$ were mainly $\mathrm{CD}^{+} 3^{+}$[7]. However, the frequencies of CD73 expressing IgM mBc [31] (Fig 2) are higher than those of cells undergoing isotype switch (Fig 5). Using a combination of CD73 with one or more of the above mentioned differentially expressed markers involved in activation, survival, or isotype switch may be useful to identify $\operatorname{IgM} \mathrm{mBc}$ that switch isotype after this stimulus.

The nature of human blood $\operatorname{IgM}^{+} \mathrm{CD} 27^{+} \mathrm{Bc}$ is a subject of controversy [11, 30]. At least a part of the subset that expresses IgD seem to be innate $\mathrm{Bc}$ with a pre-diversified repertoire of Ig $[49,50]$, which share many markers with spleen marginal zone-and similar to those present in mice-but capable of circulating in blood [10]. Besides, some studies [51], but not other [52], have shown that the $\mathrm{CD}_{2} 7^{+} \mathrm{IgM}^{+} \mathrm{IgD}^{+} \mathrm{Bc}$ are clonally related to switched $\mathrm{mBc}$, suggesting that at least a fraction of these $\mathrm{Bc}$ may be true $\mathrm{IgM} \mathrm{mBc}$. In support for this hypothesis, $\mathrm{CD}_{2} 7^{+} \mathrm{IgM}^{+} \mathrm{IgD}^{+}$cells transferred to immunodeficient mice immunized with Streptococcus pneumoniae [53] can develop specific IgG $\mathrm{mBc}$. The existence of human blood $\operatorname{IgM}^{+} \operatorname{IgD}^{+} \mathrm{mBc}$ specific for rotavirus $[17,18]$, tetanus toxoid $[17,54]$, and the D antigen [54] also suggest that at least a fraction of $\mathrm{CD} 27^{+} \mathrm{IgM}^{+} \mathrm{IgD}{ }^{+} \mathrm{Bc}$ are true $\mathrm{mBc}$. Finally, as previously mentioned, IgM 
$\mathrm{mBc}$ (excluding IgM only $\mathrm{mBc}$ ) share a similar gene expression pattern with switched $\mathrm{mBc}$ [25]. Thus, the $\mathrm{CD} 27^{+} \mathrm{IgM}^{+} \mathrm{IgD}^{+} \mathrm{Bc}$ seem to be heterogenous, a part being innate (related to marginal zone $\mathrm{Bc}$ ) while other being antigen dependent $\mathrm{mBc}$ (probably $\mathrm{GC}^{-}$) [11].

In conclusion, we have shown that a subset of $\operatorname{IgM~} \mathrm{mBc}$ rapidly proliferate and differentiate to ASC early after stimulation with $\mathrm{CpG} /$ cytokines. The functional assay we have described (Figs 4 and 5), applied to subsets of purified Bc selected based on combinations of the markers that differentiate naïve $\mathrm{Bc}$ and $\operatorname{IgM}$ and switched $\mathrm{mBc}$ (Fig 2), may be useful to identify various subpopulations among the IgM mBc.

\section{Supporting Information}

S1 Fig. Initial work-flow and pre-gating for phenotype and sorting experiments. As indicated in the figure, sorting experiments include a negative microbead enrichment step that incorporated microbeads with antibodies against CD3, CD14, CD16, and CD56. Moreover, staining for both phenotype and sorting experiments included a dump channel with antibodies against CD3, CD14, and AQUA.

S2 Fig. Phenotypic profile of the three Bc subsets. Representative histograms of the markers studied in naïve $\mathrm{Bc}$ (blue), IgM mBC (red) and $\mathrm{Sw} \mathrm{mBc}$ (green) subsets. Solid gray histogram represents fluorescence minus one (FMO).

S3 Fig. Intracellular expression of TLR9. Summary of intracellular TLR9 iMFI of naïve Bc and $\operatorname{IgM~} \mathrm{mBC}$ and $\mathrm{Sw} \mathrm{mBc}(\mathrm{n}=6)$.

S4 Fig. Proliferation kinetics and differentiation to ASC $\left(\mathrm{CD} 38^{\text {hi }} \mathrm{CD} 27^{\text {hi }}\right)$ of $\operatorname{IgM}$ and switched $\mathbf{m B c}$. Kinetic experiment of proliferation and differentiation to ASC (CD38 ${ }^{\text {hi }}$ $\mathrm{CD} 27^{\text {hi }}$ ) of IgM (brown) and switched $\mathrm{mBc}$ (blue) four days after stimulation with $\mathrm{CpG}$, a cocktail of cytokines (IL-2, IL-6, and IL-10), and murine fibroblasts (as feeder cells) for two, three, four, and five days. Kinetic experiments for early (one, two or three days) and late responses (five, seven and ten days) were also performed using ELISPOT as readout (data not shown). Since the early time point experiments showed comparable results to the flow cytometry presented in this figure and cell mortality was above $80 \%$ in the late time point experiments (data not shown), we chose day four for the experiments reported elsewhere in this paper.

S5 Fig. Post sort control for intracellular expression of IgG on sorted naïve Bc IgM mBc and Sw $\mathbf{m B c}$. Cells from a buffy coat were sorted like for the functional experiments of Figs 3 and 4 and directly stained for intracellular IgG as described for Fig 5.

(TIF)

\section{Acknowledgments}

We would like to thank the subjects that participated in this study for their generosity, the Radiotherapy Unit, Centro Javeriano de Oncología, and the Hemocentro Distrital for providing samples. 


\section{Author Contributions}

Conceived and designed the experiments: JA MF CV. Performed the experiments: CV. Analyzed the data: JA MF CV. Contributed reagents/materials/analysis tools: JA MF. Wrote the paper: JA MF CV.

\section{References}

1. Tarlinton D, Good-Jacobson K. Diversity among memory B cells: origin, consequences, and utility. Science. 2013; 341(6151):1205-11. doi: 10.1126/science.1241146 PMID: 24031013

2. Reynolds AE, Kuraoka M, Kelsoe G. Natural IgM Is Produced by CD5- Plasma Cells That Occupy a Distinct Survival Niche in Bone Marrow. J Immunol. 2014.

3. Good KL, Bryant VL, Tangye SG. Kinetics of human B cell behavior and amplification of proliferative responses following stimulation with IL-21. J Immunol. 2006; 177(8):5236-47. PMID: 17015709

4. Good KL, Avery DT, Tangye SG. Resting human memory B cells are intrinsically programmed for enhanced survival and responsiveness to diverse stimuli compared to naive B cells. J Immunol. 2009; 182(2):890-901. PMID: 19124732

5. Bernasconi NL, Traggiai E, Lanzavecchia A. Maintenance of serological memory by polyclonal activation of human memory B cells. Science. 2002; 298(5601):2199-202. PMID: 12481138

6. Pape KA, Taylor JJ, Maul RW, Gearhart PJ, Jenkins MK. Different B cell populations mediate early and late memory during an endogenous immune response. Science. 2011; 331(6021):1203-7. doi: 10. 1126/science.1201730 PMID: 21310965

7. Taylor JJ, Pape KA, Jenkins MK. A germinal center-independent pathway generates unswitched memory B cells early in the primary response. J Exp Med. 2012; 209(3):597-606. doi: 10.1084/jem. 20111696 PMID: 22370719

8. Dogan I, Bertocci B, Vilmont V, Delbos F, Megret J, Storck S, et al. Multiple layers of B cell memory with different effector functions. Nat Immunol. 2009; 10(12):1292-9. doi: 10.1038/ni.1814 PMID: 19855380

9. Kaji T, Ishige A, Hikida M, Taka J, Hijikata A, Kubo M, et al. Distinct cellular pathways select germlineencoded and somatically mutated antibodies into immunological memory. J Exp Med. 2012; 209 (11):2079-97. doi: 10.1084/jem.20120127 PMID: 23027924

10. Descatoire M, Weller S, Irtan S, Feuillard J, Storck S, Guiochon-Mantel A, et al. Identification of a human splenic marginal zone B cell precursor with NOTCH2-dependent differentiation properties. $J$ Exp Med. 2014; 211(5):987-1000. doi: 10.1084/jem.20132203 PMID: 24733829

11. Reynaud CA, Descatoire M, Dogan I, Huetz F, Weller S, Weill JC. IgM memory B cells: a mouse/human paradox. Cell Mol Life Sci. 2012; 69(10):1625-34. doi: 10.1007/s00018-012-0971-z PMID: 22481437

12. Martin F, Kearney JF. Marginal-zone B cells. Nat Rev Immunol. 2002; 2(5):323-35. PMID: 12033738

13. Klein U, Rajewsky K, Kuppers R. Human immunoglobulin (Ig)M+lgD+ peripheral blood B cells expressing the CD27 cell surface antigen carry somatically mutated variable region genes: CD27 as a general marker for somatically mutated (memory) B cells. J Exp Med. 1998; 188(9):1679-89. PMID: 9802980

14. Wirths $S$, Lanzavecchia $A$. $A B C B 1$ transporter discriminates human resting naive $B$ cells from cycling transitional and memory B cells. Eur J Immunol. 2005; 35(12):3433-41. PMID: 16259010

15. Berkowska MA, Driessen GJ, Bikos V, Grosserichter-Wagener C, Stamatopoulos K, Cerutti A, et al. Human memory $B$ cells originate from three distinct germinal center-dependent and -independent maturation pathways. Blood. 2011; 118(8):2150-8. doi: 10.1182/blood-2011-04-345579 PMID: 21690558

16. Griffin DO, Holodick NE, Rothstein TL. Human B1 cells in umbilical cord and adult peripheral blood express the novel phenotype CD20+ CD27+ CD43+ CD70. J Exp Med. 2011; 208(1):67-80. doi: 10. 1084/jem.20101499 PMID: 21220451

17. Rojas OL, Narváez CF, Greenberg HB, Angel J, Franco MA. Characterization of rotavirus specific B cells and their relation with serological memory. Virology. 2008; 380(2):234-42. doi: 10.1016/j.virol. 2008.08.004 PMID: 18789807

18. Narváez CF, Feng N, Vásquez C, Sen A, Angel J, Greenberg HB, et al. Human rotavirus-specific igm memory $B$ cells have differential cloning efficiencies and switch capacities and play a role in antiviral immunity in vivo. Journal of Virology. 2012; 86(19):10829-40. doi: 10.1128/JVI.01466-12 PMID: 22855480

19. Herrera D, Rojas OL, Duarte-Rey C, Mantilla RD, Ángel J, Franco MA. Simultaneous assessment of rotavirus-specific memory B cells and serological memory after B cell depletion therapy with rituximab. PLoS ONE. 2014; 9(5). 
20. Tian C, Luskin GK, Dischert KM, Higginbotham JN, Shepherd BE, Crowe JE Jr. Immunodominance of the $\mathrm{VH} 1-46$ antibody gene segment in the primary repertoire of human rotavirus-specific $\mathrm{B}$ cells is reduced in the memory compartment through somatic mutation of nondominant clones. J Immunol. 2008; 180(5):3279-88. PMID: 18292552

21. Amanna IJ, Slifka MK. Quantitation of rare memory B cell populations by two independent and complementary approaches. J Immunol Methods. 2006; 317(1-2):175-85. PMID: 17055526

22. Perez ME, Billordo LA, Baz P, Fainboim L, Arana E. Human memory B cells isolated from blood and tonsils are functionally distinctive. Immunol Cell Biol. 2014.

23. Shi $Y$, Agematsu K, Ochs HD, Sugane K. Functional analysis of human memory B-cell subpopulations: $\operatorname{lgD}+\mathrm{CD} 27+\mathrm{B}$ cells are crucial in secondary immune response by producing high affinity $\operatorname{lgM}$. Clin Immunol. 2003; 108(2):128-37. PMID: 12921759

24. Werner-Favre C, Bovia F, Schneider P, Holler N, Barnet M, Kindler V, et al. IgG subclass switch capacity is low in switched and in IgM-only, but high in IgD+lgM+, post-germinal center (CD27+) human B cells. Eur J Immunol. 2001; 31(1):243-9. PMID: 11265640

25. Seifert M, Przekopowitz M, Taudien S, Lollies A, Ronge V, Drees B, et al. Functional capacities of human IgM memory $B$ cells in early inflammatory responses and secondary germinal center reactions. Proc Natl Acad Sci U S A. 2015; 112(6):E546-55. doi: 10.1073/pnas.1416276112 PMID: 25624468

26. Vicetti Miguel RD, Hendricks RL, Aguirre AJ, Melan MA, Harvey SA, Terry-Allison T, et al. Dendritic cell activation and memory cell development are impaired among mice administered medroxyprogesterone acetate prior to mucosal herpes simplex virus type 1 infection. J Immunol. 2012; 189(7):3449-61. PMID: 22942424

27. Darrah PA, Patel DT, De Luca PM, Lindsay RW, Davey DF, Flynn BJ, et al. Multifunctional TH1 cells define a correlate of vaccine-mediated protection against Leishmania major. Nat Med. 2007; 13 (7):843-50. PMID: 17558415

28. Quah BJ, Parish CR. The use of carboxyfluorescein diacetate succinimidyl ester (CFSE) to monitor lymphocyte proliferation. J Vis Exp. 2010(44:).

29. Isnardi I, Ng YS, Menard L, Meyers G, Saadoun D, Srdanovic I, et al. Complement receptor 2/CD21human naive B cells contain mostly autoreactive unresponsive clones. Blood. 2010; 115(24):5026-36. doi: 10.1182/blood-2009-09-243071 PMID: 20231422

30. Cerutti A, Cols M, Puga I. Marginal zone B cells: virtues of innate-like antibody-producing lymphocytes. Nat Rev Immunol. 2013; 13(2):118-32. doi: 10.1038/nri3383 PMID: 23348416

31. Schena F, Volpi S, Faliti CE, Penco F, Santi S, Proietti M, et al. Dependence of immunoglobulin class switch recombination in $B$ cells on vesicular release of ATP and CD73 ectonucleotidase activity. Cell reports. 2013; 3(6):1824-31. doi: 10.1016/j.celrep.2013.05.022 PMID: 23770243

32. Koncz G, Hueber AO. The Fas/CD95 Receptor Regulates the Death of Autoreactive B Cells and the Selection of Antigen-Specific B Cells. Front Immunol. 2012; 3:207. doi: 10.3389/fimmu.2012.00207 PMID: 22848207

33. Yates JL, Racine R, McBride KM, Winslow GM. T Cell-Dependent IgM Memory B Cells Generated during Bacterial Infection Are Required for IgG Responses to Antigen Challenge. J Immunol. 2013; 191 (3):1240-9. doi: 10.4049/jimmunol.1300062 PMID: 23804710

34. Thibult ML, Mamessier E, Gertner-Dardenne J, Pastor S, Just-Landi S, Xerri L, et al. PD-1 is a novel regulator of human B-cell activation. International immunology. 2013; 25(2):129-37. doi: 10.1093/ intimm/dxs098 PMID: 23087177

35. Ruffin N, Lantto R, Pensieroso S, Sammicheli S, Hejdeman B, Rethi B, et al. Immune activation and increased IL-21R expression are associated with the loss of memory B cells during HIV-1 infection. Journal of internal medicine. 2012; 272(5):492-503. doi: 10.1111/j.1365-2796.2012.02550.x PMID: 22530560

36. Moens L, Tangye SG. Cytokine-Mediated Regulation of Plasma Cell Generation: IL-21 Takes Center Stage. Front Immunol. 2014; 5:65. doi: 10.3389/fimmu.2014.00065 PMID: 24600453

37. Hawkins ED, Turner ML, Wellard CJ, Zhou JH, Dowling MR, Hodgkin PD. Quantal and graded stimulation of $B$ lymphocytes as alternative strategies for regulating adaptive immune responses. Nature communications. 2013; 4:2406. doi: 10.1038/ncomms3406 PMID: 24009041

38. Tangye SG, Avery DT, Deenick EK, Hodgkin PD. Intrinsic differences in the proliferation of naive and memory human $B$ cells as a mechanism for enhanced secondary immune responses. J Immunol. 2003; 170(2):686-94. PMID: 12517929

39. Deenick EK, Avery DT, Chan A, Berglund LJ, Ives ML, Moens L, et al. Naive and memory human B cells have distinct requirements for STAT3 activation to differentiate into antibody-secreting plasma cells. J Exp Med. 2013; 210(12):2739-53. doi: 10.1084/jem.20130323 PMID: 24218138 
40. Bryant VL, Ma CS, Avery DT, Li Y, Good KL, Corcoran LM, et al. Cytokine-mediated regulation of human $B$ cell differentiation into Ig-secreting cells: predominant role of IL-21 produced by CXCR5+ T follicular helper cells. J Immunol. 2007; 179(12):8180-90. PMID: 18056361

41. Geffroy-Luseau A, Chiron D, Descamps G, Jego G, Amiot M, Pellat-Deceunynck C. TLR9 ligand induces the generation of CD20+ plasmablasts and plasma cells from CD27+ memory B-cells. Front Immunol. 2011; 2:83. doi: 10.3389/fimmu.2011.00083 PMID: 22566872

42. Pone EJ, Zan H, Zhang J, Al-Qahtani A, Xu Z, Casali P. Toll-like receptors and B-cell receptors synergize to induce immunoglobulin class-switch DNA recombination: relevance to microbial antibody responses. Crit Rev Immunol. 2010; 30(1):1-29. PMID: 20370617

43. Kotlarz D, Zietara N, Uzel G, Weidemann T, Braun CJ, Diestelhorst J, et al. Loss-of-function mutations in the IL-21 receptor gene cause a primary immunodeficiency syndrome. J Exp Med. 2013; 210 (3):433-43. doi: 10.1084/jem.20111229 PMID: 23440042

44. Klein U, Tu Y, Stolovitzky GA, Keller JL, Haddad J Jr., Miljkovic V, et al. Transcriptional analysis of the B cell germinal center reaction. Proc Natl Acad Sci U S A. 2003; 100(5):2639-44. PMID: 12604779

45. Bernasconi NL, Onai N., and Lanzavecchia A. A role for Toll-like receptors in acquired immunity: upregulation of TLR9 by $B C R$ triggering in naive $B$ cells and constitutive expression in memory $B$ cells. Blood. 2003; 101:4500-4. PMID: 12560217

46. Nutt SL, Tarlinton DM. Germinal center B and follicular helper T cells: siblings, cousins or just good friends? Nat Immunol. 2011; 12(6):472-7. PMID: 21739669

47. Litinskiy MB, Nardelli B, Hilbert DM, He B, Schaffer A, Casali P, et al. DCs induce CD40-independent immunoglobulin class switching through BLyS and APRIL. Nat Immunol. 2002; 3(9):822-9. PMID: 12154359

48. He B, Qiao X, Cerutti A. CpG DNA induces IgG class switch DNA recombination by activating human B cells through an innate pathway that requires TLR9 and cooperates with IL-10. J Immunol. 2004; 173 (7):4479-91. PMID: 15383579

49. Weller S, Mamani-Matsuda M, Picard C, Cordier C, Lecoeuche D, Gauthier F, et al. Somatic diversification in the absence of antigen-driven responses is the hallmark of the $\lg M+\lg D+C D 27+B$ cell repertoire in infants. J Exp Med. 2008; 205(6):1331-42. doi: 10.1084/jem.20071555 PMID: 18519648

50. Weller S, Faili A, Garcia C, Braun MC, Le Deist FF, de Saint Basile GG, et al. CD40-CD40L independent Ig gene hypermutation suggests a second $B$ cell diversification pathway in humans. Proc Natl Acad Sci U S A. 2001; 98(3):1166-70. PMID: 11158612

51. Seifert M, Kuppers R. Molecular footprints of a germinal center derivation of human IgM+(IgD+)CD27+ $B$ cells and the dynamics of memory B cell generation. J Exp Med. 2009; 206(12):2659-69. doi: 10. 1084/jem.20091087 PMID: 19917772

52. Wu YC, Kipling D, Leong HS, Martin V, Ademokun AA, Dunn-Walters DK. High-throughput immunoglobulin repertoire analysis distinguishes between human IgM memory and switched memory B-cell populations. Blood. 2010; 116(7):1070-8. doi: 10.1182/blood-2010-03-275859 PMID: 20457872

53. Moens L, Wuyts M, Meyts I, De Boeck K, Bossuyt X. Human memory B lymphocyte subsets fulfill distinct roles in the anti-polysaccharide and anti-protein immune response. J Immunol. 2008; 181 (8):5306-12. PMID: 18832686

54. Della Valle L, Dohmen SE, Verhagen OJ, Berkowska MA, Vidarsson G, Ellen van der Schoot C. The majority of human memory $\mathrm{B}$ cells recognizing $\mathrm{RhD}$ and tetanus resides in IgM+ B cells. J Immunol 2014; 193(3):1071-9. doi: 10.4049/jimmunol.1400706 PMID: 24965774 